\title{
Ti-Containing Mesoporous Organosilica as a Photocatalyst for Selective Olefin Epoxidation
}

Masatsugu Morishita, Yasuhiro Shiraishi, ${ }^{*}$ and Takayuki Hirai

Research Center for Solar Energy Chemistry, and Division of Chemical Engineering, Graduate School of Engineering Science, Osaka University, Toyonaka 560-8531, Japan

\section{Supporting Information}

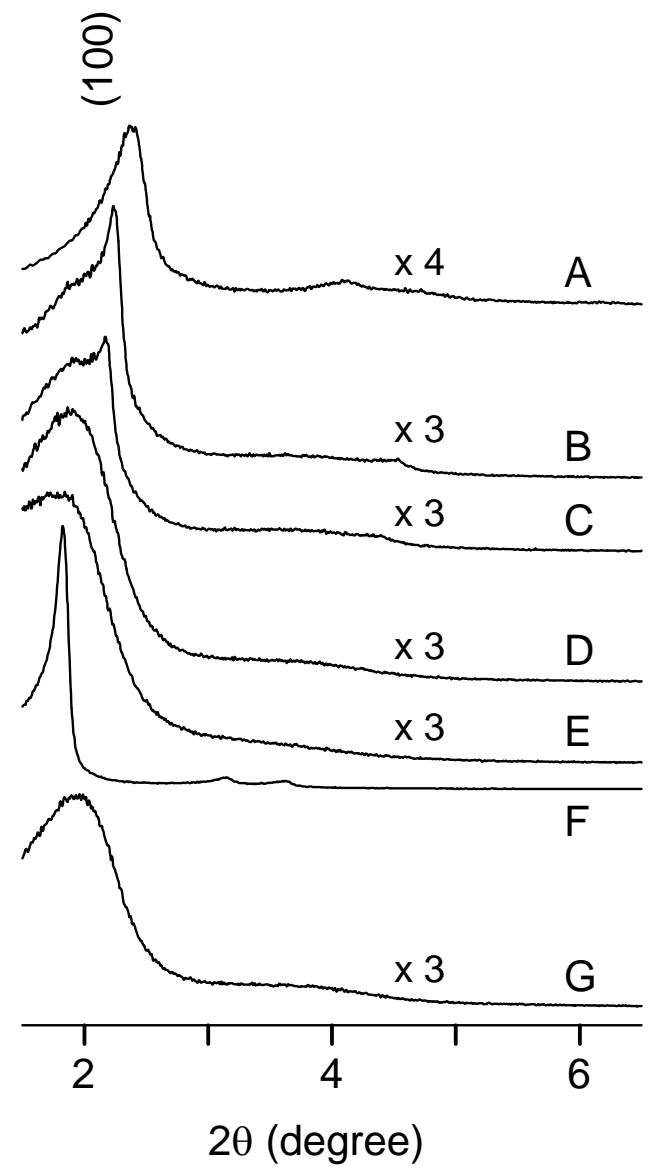

Figure S1. Powder XRD patterns of catalysts. (A) T-S, (B) T-OS(2), (C) T-OS(5), (D) T-OS(10), (E) T-OS(20) catalysts, (F) T-OS(100), and (G) T-OS(10)-Cal. 

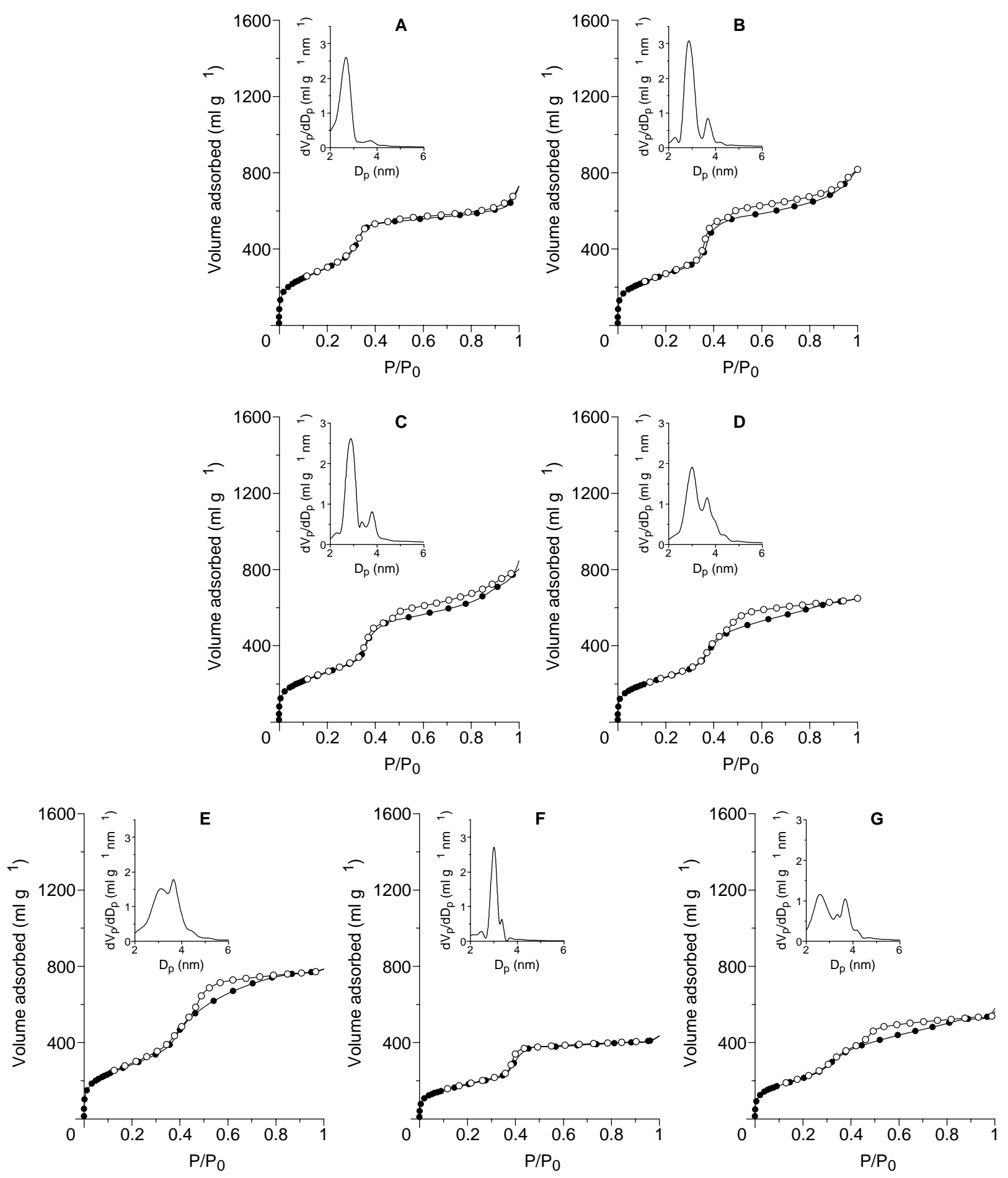

Figure S2. $\mathrm{N}_{2}$ adsorption( $\bullet$ )-desorption( $(\circ)$ isotherm and pore size distribution (inset) of the catalysts. (A) T-S, (B) T-OS(2), (C) T-OS(5), (D) T-OS(10), (E) T-OS(20), (F) T-OS(100), (G) T-OS(10)-Cal. 


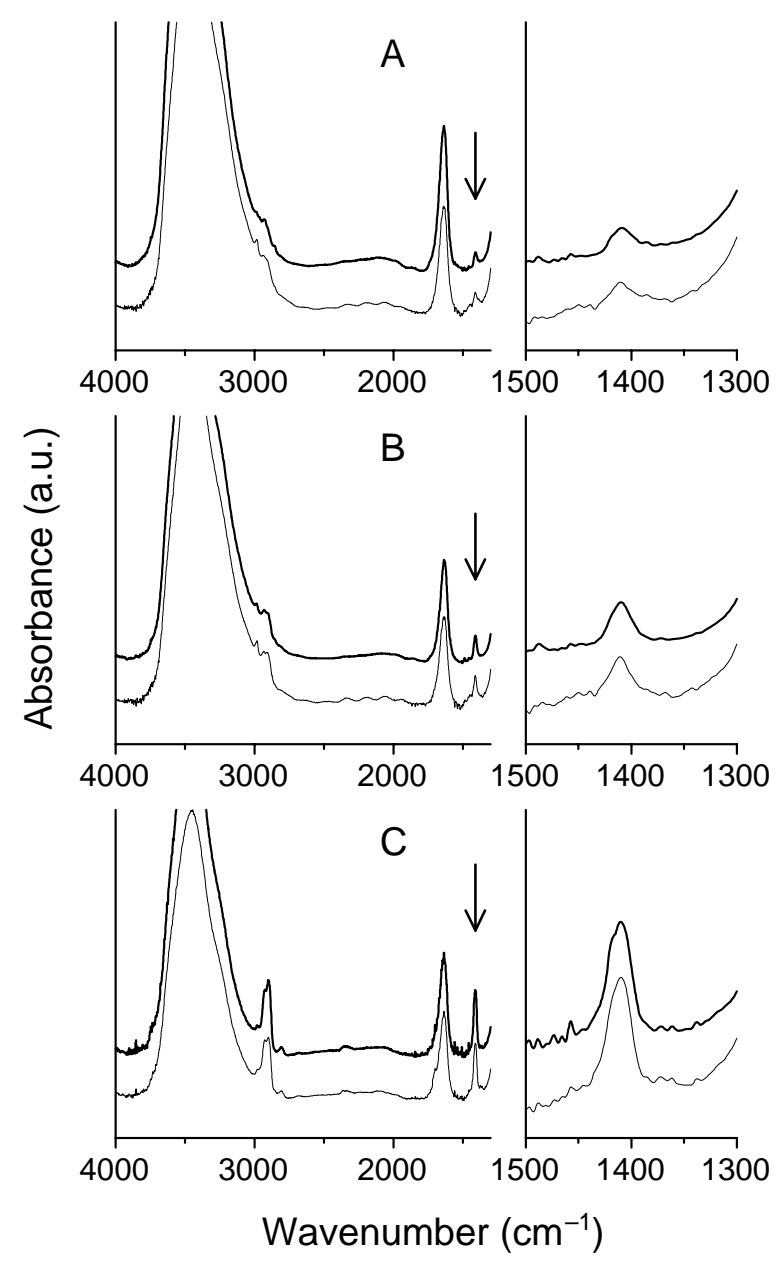

Figure S3. IR spectra of (A) T-OS(10), (B) T-OS(20), and (C) T-OS(100) catalysts, measured (bold line) before reaction and (solid line) after reaction with $\mathrm{MeCN}$. The reaction conditions are identical to that in Table 2.
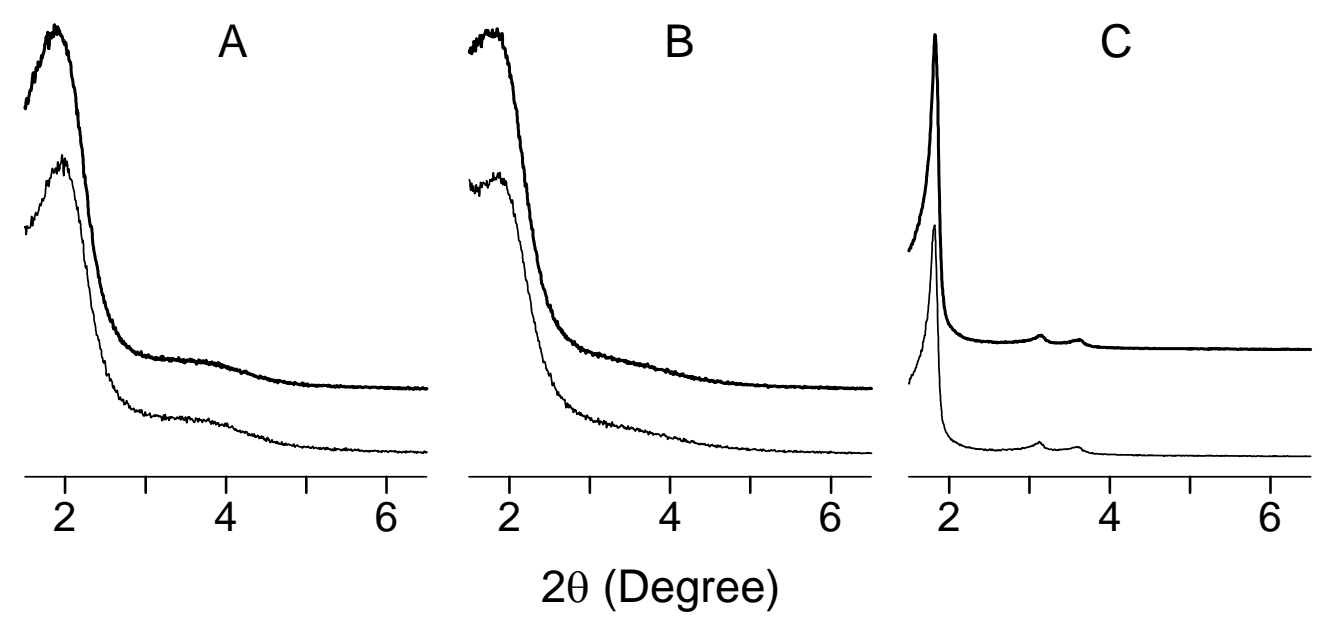

Figure S4. Powder XRD patterns of (A) T-OS(10), (B) T-OS(20), (C) T-OS(100) catalysts measured (bold line) before reaction and (solid line) after reaction with $\mathrm{MeCN}$. The reaction conditions are identical to that in Table 2. 